\title{
El conocimiento ficcional como forma de acercamiento al conocimiento del mundo real: reclasificación de los tipos de conocimiento, caracterización y fundamentos para un enfoque lingüístico
}

\section{Fictional knowledge as a means of acquiring knowledge of the real world: a reclassification and characterisation of types of knowledge from a linguistic approach}

\author{
Sergio Rodríguez Tapia/María del Carmen Moreno Paz \\ sergio.rodriguez@uco.es/l02mopam@uco.es \\ Universidad de Córdoba
}

Fecha de recepción: 31 de agosto de 2018

Fecha de aceptación: 31 de octubre de 2018

Resumen: Partiendo de la clasificación binaria de los tipos de conocimiento general sobre la realidad entre el conocimiento común y el conocimiento especializado, el presente trabajo tiene como objetivo proponer una nueva categorización de los tipos de conocimiento, añadiendo la nueva categoría de conocimiento ficcional al mismo nivel que el conocimiento común y el conocimiento especializado. El motivo de esta propuesta de reclasificación reside en nuestra hipótesis de que la ficción supone otra forma de acercamiento al conocimiento general que no puede adscribirse a ninguna de las otras dos categorías anteriores debido a la existencia de lagunas metodológicas en cuanto a los parámetros comúnmente utilizados para la caracterización de los tipos de conocimiento Basándonos en las aportaciones de la filosofía del lenguaje y la teoría de la ficción, comprobamos que se trata de un tipo de discurso distinto de otros por sus características pragmáticas y relacionales (particularmente con respecto a los valores de referencialidad al mundo real). Por tanto, consideramos necesario proponer una nueva reestructuración de los tipos de conocimiento, así como caracterizar el conocimiento ficcional utilizando un enfoque integrador que recurra a la lingüística, la terminología y la filosofía del lenguaje para poder aproximarnos a una concepción del conocimiento general más abarcadora y representativa de la realidad.

Palabras clave: conocimiento general, conocimiento especializado, conocimiento común, conocimiento ficcional, ficción. 
Abstract: Taking into account the dual classification of general knowledge about reality (commonly divided into common knowledge and specialised knowledge), the present work aims at establishing a new categorisation of the types of knowledge, adding the category of fictional knowledge at the same level as common knowledge and specialised knowledge. Our hypothesis is that fiction also constitutes a means of approaching general knowledge. Nevertheless, we have observed some methodological gaps in the parameters currently used for the characterisation of types of knowledge that make it not possible to include fiction in any of the aforementioned categories. Furthermore, when examining the studies on philosophy of language and theory of fiction, we can realise that fictional discourse differs considerably from other types of discourse due to its pragmatic and relational values (particularly, with regard to reference values to real world). Consequently, a reorganisation of the types of knowledge seems necessary. For this purpose, we will define and characterise the new category of fictional knowledge using an interdisciplinary approach that integrates linguistics, terminology and philosophy of language, which could eventually allow us to approach a more comprehensive and representative concept about general knowledge.

Keywords: general knowledge, specialised knowledge, common knowledge, fictional knowledge, fiction.

\section{INTRODUCCIÓN. MOTIVACIÓN CIENTÍFICA DEL ESTUDIO}

La división binaria en conocimiento común y conocimiento especializado (Cabré et al., 2001) resulta de gran relevancia teórica en los estudios sobre terminología, puesto que, a partir del reconocimiento de sus imbricaciones, permite estudiar la interdependencia de dichos tipos de conocimiento a partir de material textual real. Sin embargo, en trabajos anteriores (Moreno Paz y Rodríguez-Tapia, 2016), se ha defendido la existencia de un nuevo tipo de conocimiento, que denominamos conocimiento ficcional ${ }^{1}$, que comparte estrecha relación con el conocimiento especializado y el conocimiento común pero que posee cualidades particulares, de forma que es posible defender una nueva estructuración de los tipos de conocimiento, más explicativa del uso textual real.

\footnotetext{
${ }^{1}$ Preferimos utilizar el adjetivo ficcional a ficticio, ya que el primero se ajusta más a la definición que manejamos en el presente trabajo (definido por el Diccionario de la Real Academia Española como 'perteneciente o relativo a la ficción'). El adjetivo ficticio, sin embargo, se define como 'fingido, imaginario o falso'. Queremos evitar, pues, que se pueda interpretar como un tipo de conocimiento sobre lo inventado o falso, ya que nos referiremos en adelante al conocimiento que se adquiere sobre la ficción.
} 
Así, de igual forma a cómo el conocimiento especializado parte de una reformulación del conocimiento común para explicar nuevas realidades, el conocimiento ficcional parte del conocimiento común para acercarse a la realidad, conocer el mundo factual y explicar los hechos reales de forma metafórica, abstracta o mimética.

Se trata, en definitiva, de un tipo de conocimiento distinto del común y del especializado, puesto que, a diferencia de estos, no hace referencia a realidades materiales 0 inmateriales, sino que alude a conceptos que no existen en el mundo factual pero que pueden ser materializables (posibles) 0 inmaterializables (imposibles), que tienen sentido en un constructo semiótico determinado dentro de una obra de ficción y que, sin embargo, son comprendidos por el receptor.

\section{HIPÓTESIS Y OBJETIVOS}

Si bien en estudios anteriores se han realizado aproximaciones al concepto de conocimiento ficcional y a su caracterización con respecto a otros tipos de conocimiento (Moreno Paz y Rodríguez-Tapia, 2016), así como también existen trabajos que reflexionan sobre el estatuto ontológico de la ficción (Garrido Domínguez, 1997), en el presente trabajo pretendemos justificar la necesidad de una nueva clasificación, basándonos en los siguientes presupuestos:

a) Es posible diseñar un esquema de estructuración de los tipos de conocimiento atendiendo a una división multicriterio, que incluya, además de las categorías de conocimiento común y conocimiento especializado, la categoría de conocimiento ficcional.

b) El conocimiento común es el punto de encuentro del conocimiento de lo real o factual y del conocimiento de lo irreal o imaginario.

c) La motivación ontológica y epistemológica de la división de los tipos de conocimiento es de carácter instrumental o funcional.

Teniendo en mente dichas hipótesis, el propósito del presente trabajo puede resumirse en los objetivos siguientes:

a) Analizar el estado de la cuestión en torno a los tipos de conocimiento y las relaciones entre ellos que son explicativas para la lingüística.

b) Justificar la necesidad de reclasificar los tipos de conocimiento resaltando algunas de las principales lagunas metodológicas en 
los parámetros de identificación del conocimiento común y del conocimiento especializado.

c) Determinar la relación que existe entre el conocimiento ficcional y el conocimiento del mundo según la referencialidad de la ficción y su aproximación a la realidad.

d) Justificar la ubicación del conocimiento ficcional en relación con el conocimiento especializado y el conocimiento común en una nueva estructuración conceptual.

3. EL MARCO DE PARTIDA: LA INTERRELACIÓN DEL CONOCIMIENTO COMÚN Y EL CONOCIMIENTO ESPECIALIZADO

Desde nuestro punto de vista, los contextos o situaciones especializadas, donde tienen uso los textos especializados, se caracterizan por la representación y transmisión del denominado conocimiento especializado, lo que nos acerca a la posición de Cabré et al. (2001). En este estudio:

[...] partimos del hecho de que el conocimiento no es un objeto estático que pueda identificarse de forma unívoca con una disciplina, sino que se trata de una red de conexiones interrelacionadas entre sí, lo que explica, por ejemplo, el surgimiento de nuevas disciplinas, como la socioterminología, o de nuevos mecanismos de transmisión de información, como la banalización y la terminologización. En esta red de imbricaciones, Cabré et al. (2001) distinguen dos tipos de conocimiento: especializado y general (al que nosotros denominaremos conocimiento común siguiendo la calificación que otorga Hoffmann (1999 [1985]) a las lenguas o discursos: Gesamtsprache (lengua general), Fachsprache (lengua especializada, o desde nuestro punto de vista, discurso especializado) y Gemeinsprache (lengua común) (Rodríguez-Tapia 2016, 989).

Aun reconociendo la falta de límites entre estos dos tipos de conocimiento, es posible aproximarse a las características esenciales atribuibles al conocimiento especializado y común (de aquí en adelante, CE y CC, respectivamente). Como se mencionaba antes, partimos de las situaciones de comunicación, en las que deben tenerse en cuenta las condiciones de emisión, de recepción, la función comunicativa básica y la temática (Cabré y Estopà, 2005: 69). Si tomamos como punto de partida caracterizador la comunicación especializada:

a) En cuanto a las condiciones de emisión: es necesario que el emisor controle bien la estructura conceptual del ámbito (Cabré y Estopà, 2005: 69; Cabré, 2002). 
b) En cuanto a las condiciones de recepción, y, en especial, en cuanto al receptor: Cabré y Estopà (ídem) defienden que el CE queda caracterizado por «el hecho de tener expectativa de recibir información, de ser informado, expectativa que no se da en otras situaciones comunicativas cuyo propósito general es de otra índole». No obstante, consideramos que la expectativa de ser informado también se da en otras situaciones comunicativas (al leer la prensa o consultar un manual, por ejemplo). Sin embargo, al ser un tipo de conocimiento restringido al ámbito de especialidad, está destinado a un público concreto que accede al texto con la expectativa de ser informado.

c) En cuanto a la función básica: la comunicación especializada se inclina hacia la representación de dicho conocimiento, diferenciándose del discurso común, que puede poner en funcionamiento diferentes funciones (como la emotiva, la estética, etc.).

d) En cuanto a la temática y, en concreto, en relación con el conocimiento transmitido: solo será posible clasificar un conocimiento como especializado "si se representa y si se transmite respetando escrupulosamente la estructura conceptual del campo en cuestión» (Cabré y Estopà, 2005: 70). Junto con la estructura formal (que se relaciona con el género textual de cada texto) y la gramatical, las mencionadas autoras vinculan al texto especializado la «estructura informativa, mejor denominada cognitiva, que representa el conocimiento transmitido por el texto" (ídem).

Si recurrimos al trabajo de Cabré et al. (2001: 178), centrado en las diferencias entre CE y CC, observamos que «el conocimiento general [para nosotros conocimiento común], en analogía con la competencia lingüística, es la información que el individuo medio comparte con los otros en virtud de su pertenencia a una comunidad, una cultura y una época determinadas", en contraste con el conocimiento especializado, que se caracteriza «por una estructuración más sistemática de sus contenidos» (Cabré et al., 2001: 174) y una perspectiva diferente desde la que se aborda la materia (Cabré et al., 2001: 178) (Rodríguez-Tapia, 2016: 989). Además, sostienen que el CE no constituye un conocimiento totalmente nuevo, ya que parte de un conocimiento previo (del CC) ${ }^{2}$, es decir, se trata de una reformulación en diferentes grados (lo que explica la dificultad para marcar límites) del CC

2 Como trataremos más adelante, esta reformulación constituye un punto en común con el conocimiento ficcional. 
anterior. Por esta razón, a nuestro juicio (ídem), es posible percibir una relación de inclusión del CE y del CC dentro de la categoría conocimiento general (CG), que hace referencia al conocimiento de toda la realidad como un todo integrador (Montero y Faber, 2008: 75-76).

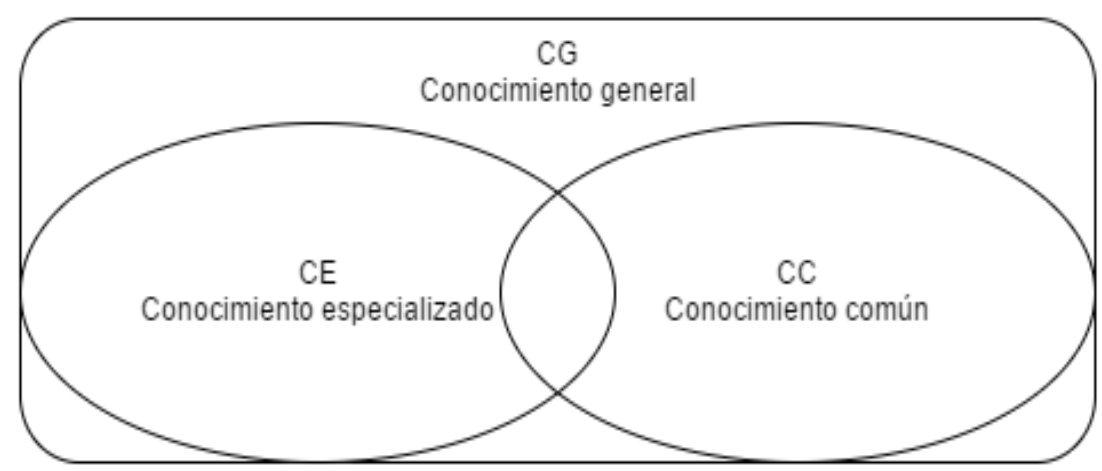

Figura 1. Relación entre el CE y el CC

Fuente: elaboración propia

A modo de resumen del mencionado trabajo de Cabré et al. (2001), y seleccionando los datos más pertinentes para este estudio, sintetizamos las características del CC y el CE en la siguiente tabla:

\begin{tabular}{|c|c|}
\hline Conocimiento común & Conocimiento especializado \\
\hline $\begin{array}{l}\text { Es el conocimiento compartido por } \\
\text { una cultura, adquirido por el individuo } \\
\text { desde su inserción y convivencia en } \\
\text { la sociedad, y consolidado de manera } \\
\text { no sistemática a partir de la } \\
\text { experiencia con el mundo. Se } \\
\text { estructura según el tiempo y los } \\
\text { procesos históricos que permiten } \\
\text { organizar la información según lo que } \\
\text { aporta la experiencia al individuo. }\end{array}$ & $\begin{array}{l}\text { No forma parte del bagaje común del } \\
\text { individuo medio y representa una } \\
\text { segmentación voluntaria y } \\
\text { consciente de una parcela de la } \\
\text { realidad. Asimismo, se inserta en } \\
\text { contextos de instrucción explícitos y } \\
\text { su adquisición parte de la } \\
\text { reformulación del conocimiento } \\
\text { general a partir de la experiencia del } \\
\text { individuo con el mundo y se basa } \\
\text { principalmente en la aceptación de } \\
\text { hipótesis y enunciados que se basan } \\
\text { en teorías sobre qué es y cómo } \\
\text { funciona la realidad. Estas hipótesis } \\
\text { se someten a prueba empírica, }\end{array}$ \\
\hline
\end{tabular}




\begin{tabular}{|l|l|}
\hline & $\begin{array}{l}\text { coherencia lógica o funcionalidad } \\
\text { práctica. }\end{array}$ \\
\hline
\end{tabular}

TABLA 1. Caracterización del CC y el CE.

Fuente: adaptado de Cabré et al. (2001: 174 y ss.)

En cierto sentido, la diferencia principal entre el CE y el CC se halla en la estructuración sistemática del primero con respecto del segundo (Cabré et al. 2001, 174). Si relacionamos esta idea con la noción de valor especializado (activado por condicionantes pragmático-cognitivos; Adelstein, 2004: 7; Cabré y Estopà, 2002, 146), este valor quedaría activo si la unidad transmite CE.

\section{APROXIMACIÓN AL CONCEPTO DE CONOCIMIENTO FICCIONAL: UBICACIÓN EN EL MARCO DE PARTIDA Y PROBLEMAS EN LA CLASIFICACIÓN}

Existe cierto tipo de conocimiento que, aun partiendo del $\mathrm{CC}$, incluyéndose en el CG y estando sometido al control sistemático, no cumple con algunos criterios del CE. Piénsese, por ejemplo, en el discurso ficcional ${ }^{3}$. Este tipo de discurso controla sus denominaciones y sus sistemas conceptuales (que son artificiales, ficcionales, aunque se basan en sistemas conceptuales reales; i. e. constituyen una reformulación del CC compartido por toda la sociedad o por una parte de ella).

\footnotetext{
${ }^{3}$ Aunque no es nuestro objetivo realizar una aproximación al estatus ontológico y semántico de la ficción (cuestión ampliamente abordada en otras disciplinas como la teoría literaria y la filosofía del lenguaje), sí consideramos conveniente matizar que entendemos por ficción un tipo de discurso que se diferencia de otros por sus condicionantes pragmáticos de producción, y no sus valores formales o semánticos. Nos adscribimos, en este sentido, a la hipótesis más aceptada en filosofía del lenguaje: la «teoría de la pretensión» (pretense theory), establecida en el marco de la teoría de los actos de habla y defendida, entre otros, por autores como John Searle (1992). Según esta teoría, en la ficción no se producen actos de habla diferentes de aquellos del discurso no ficcional, sino que estos actos de habla se realizan con una actitud de "simulación» o «pretensión». Se trata, además, de un fenómeno creativo que surge a raíz de la intención de un individuo con la intención de comunicar acciones imaginarias como si se tratara de acciones reales, con una función principalmente estética y una motivación lúdica. Esto implica, por lo tanto, que se puede manifestar en forma de textos (literarios, aunque ello no presupone la total identificación del concepto de literatura y ficción), producciones audiovisuales (cine, series, videojuegos), imágenes (pintura, cómics, etc.).
}

Hikma 17 (2018), 145 - 173 
Puede que uno de los argumentos a favor de no considerar estos objetos dentro del CE se halle en el tipo de destinatario: se trata de objetos orientados al público general, que no necesita una instrucción previa en dicho conocimiento. No obstante, los objetos que codifica el CF, en algunos casos, sí que pueden considerarse como objetos de orientación restringida a un receptor concreto (condicionado por variación diageneracional y diastrática fundamentalmente, y no por variación diafásica como el CE). En efecto, si nos basamos en el concepto de semioesfera de Lotman (1990: 123-125, 131136), es posible defender que cualquier receptor podría, por ejemplo, leer Cuento de Navidad de Charles Dickens o Fundación de Isaac Asimov, pero sin la competencia necesaria (es decir, sin el conocimiento de la semiosfera: normas, convenciones, reglas, etc. que afectan a subconjuntos culturales, entre los que se incluyen la historia o literatura), el receptor no podrá comprender por completo dicho CF.

Otro argumento que justifica esta consideración se encuentra en la función, que se inclina hacia una función estética y conativa, principalmente lúdica, en el caso del CF, y no hacia la representación del conocimiento (función referencial principalmente, que suelen cumplir los textos especializados) ${ }^{4}$. No obstante, conviene matizar que, en el caso del CF, la representación del conocimiento es previa porque el mundo ficcional debe construirse antes de que exista ese conocimiento. Dicho de otro modo, mientras que el CE se orienta a la representación de una realidad ya existente (la que nos rodea), el CF responde a una motivación lúdica que surge como resultado de la creatividad del autor, que debe construir un conocimiento previamente inexistente (aunque basado en su conocimiento del mundo real).

Si recurrimos a las características del CE esbozadas con anterioridad (Cabré et al., 2001) e intentamos vincularlas con dichas narrativas o campos conceptuales (pongamos por ejemplo El Señor de los Anillos o Un Mundo Feliz), se observan algunas coincidencias con el CE, como por ejemplo:

a) Que no forma parte del bagaje común del individuo medio.

b) Que constituye una segmentación voluntaria y consciente de una parcela de la realidad ${ }^{5}$.

\footnotetext{
${ }^{4}$ Si bien la función de la ficción continúa siendo objeto de debate, ya que en la teoría literaria y filosofía del lenguaje se discute si la ficción posee una función representativa de la realidad (lo que implicaría aceptar la teoría mimética) o una función puramente estética, consideramos, como Frye (1957: 75), que la ficción puede tener una función representativa de la realidad, pero esta está subordinada a su valor estético o lúdico.

${ }^{5}$ Podría defenderse la idea de que se trata de una segmentación voluntaria y consciente de una parcela de la realidad, puesto que sería posible dividir la realidad en el mundo factual y el mundo ficcional o imaginario. Asimismo, se trata de una segmentación voluntaria y consciente de la
} 
c) Que su adquisición parte de la reformulación del CC y, además, es voluntaria.

Asimismo, otras características atribuibles al CE parece que no tienen cabida en el conocimiento codificado en estas narrativas, por lo que, desde nuestra perspectiva, constituyen claras diferencias. Con respecto a la relación del CF con el CE, no es posible defender:

a) Que el CF surja a partir de la aceptación de hipótesis y enunciados.

b) Que dichas hipótesis estén sometidas a prueba empírica, coherencia lógica y funcionalidad práctica.

c) Que la función principal del CF sea una función primordialmente referencial y no lúdica.

También consideramos que sería posible incluso hacer referencia a un triple sentido del término especializado (una decisión poco recomendable en terminología, como defienden las teorías que favorecen la biunivocidad):

a) El primer sentido podría relacionarse con el control conceptual y es el que viene desarrollándose en terminología desde sus inicios, es decir, se califica algo de especializado porque está sometido al control conceptual por parte de especialistas.

b) El segundo podría relacionarse con el principio de relevancia y con la densidad cognitiva, es decir, con qué considera el usuario receptor que es especializado según un criterio psicológico (es decir, subjetivo) y basándose en el criterio de comprensibilidad (Heller, 1970: 532).

c) Otra perspectiva, más cercana a la traductología, se posiciona a favor de la clasificación de un texto como especializado cuando dicho texto posee ciertas características particulares que no comparte con otros tipos de texto y que hace necesario llevar a cabo técnicas o seguir estrategias de traducción conforme a la especificidad del tipo de texto (por ejemplo, literario, publicitario o multimedia, entre otros). No obstante, este criterio, casi de forma automática, hace que se deba incluir cualquier texto en la categoría de texto especializado, ya que todos los tipos textuales se oponen por características pertinentes, es decir, particulares, lo que, en principio, hace innecesario diseñar un subtipo de texto

realidad porque el autor crea una irrealidad limitada basándose en la realidad (al vivir en el mundo, está condicionado por él). 
(el especializado) que aglutine a todos los textos de la categoría superior (el supertipo texto).

En los siguientes ejemplos ${ }^{6}$ se pueden apreciar diferentes unidades léxicas que, siguiendo el criterio de comprensibilidad del segundo sentido de especializado anteriormente mencionado, podrían considerarse en el extremo de no comprensible para todo el mundo del modelo de Heller ${ }^{7}$ :

a) «[...] Polífago azul. Consumible. Lo puede usar tu Espectro para reunir más lumen de los vex enemigos. Dura 10 minutos» (Bungie, 2014, Destiny, PS4).

b) «-Esta dorada - continuó Wood-es la snitch. Es la pelota más importante de todas. Cuesta mucho de atrapar por lo rápida y difícil de ver que es. El trabajo del buscador es atraparla. Tendrás que ir y venir entre cazadores, golpeadores, la quaffle y las bludgers, antes de que la coja el otro buscador [...]» (Rowling, 2001: 143-144, Harry Potter y la piedra filosofal, cap. 10).

c) «Se llamaba Gaal Dornick y no era más que un campesino que nunca había visto Trántor. Es decir, no realmente. Lo había visto muchas veces en el hipervídeo, [...]. A pesar de haber vivido siempre en el mundo de Synnax, que giraba alrededor de una estrella al borde del Cúmulo Azul, no estaba desconectado de la civilización» (Asimov, 1951, Fundación, cap. 1).

d) «Un hombre con un deslumbrante uniforme azul y amarillo, hecho de plastrotextil a prueba de manchas, se hizo cargo de sus dos bolsas. -Línea directa al Luxor- dijo». (Asimov, 1951, Fundación, cap. 2).

Si el criterio aplicable a la clasificación de una unidad léxica como término se encuadra en la comprensibilidad o grado de comprensibilidad de

6 La elección de estos ejemplos no pretende condicionar ni limitar la categorización de conocimiento ficcional a un tipo concreto de discurso literario (por ejemplo, de ciencia-ficción o fantasía). En este sentido, conviene matizar que la ficción no se manifiesta únicamente en textos literarios (puede observarse, por ejemplo, en cómics, videojuegos o cine), ni tampoco en géneros como el fantástico o de ciencia-ficción. No obstante, hemos escogido estos ejemplos para mostrar casos evidentes de creaciones neológicas no comprensibles para todo el mundo que, debido a que se insertan en narrativas situadas en mundos ficcionales distintos del mundo real, resultan a su vez más alejadas para la comprensión.

${ }^{7}$ Como manifestamos en otros trabajos (Moreno Paz y Rodríguez-Tapia, 2018), otra coincidencia entre el CE y el CF se halla en los mecanismos de formación de unidades léxicas de sus respectivas denominaciones: en los siguientes ejemplos es posible apreciar sintagmación (Saeta de Fuego), composición actual (giratiempo), composición culta (mortífago) o calco por ampliación semántica (traslador). 
la misma, pensar en ejemplos como los siguientes podría llevarnos a pensar que se trata de unidades no comprensibles para todo el mundo, como puede ocurrir asimismo con otros vocablos propios del argot o la jerga, debido a su densidad cognitiva, opacidad morfológica o escasa frecuencia en el discurso común, lo que hace que no sean necesariamente comprensibles para el individuo medio:

a) El descubrimiento de la penicilina fue una serendipia (RAE 2014).

b) Burdégano: 1. m. Hijo de caballo y burra, casi siempre estéril, como los mulos, y con la cabeza más grande y el cuerpo más pequeño que estos (RAE, 2014).

c) Melifluo: 2. adj. Dulce, suave, delicado y tierno en el trato o en la manera de hablar (RAE, 2014).

Efectivamente, no podría defenderse que dichas unidades léxicas fuesen términos, puesto que no codifican $\mathrm{CE}$, un conocimiento controlado y con un fin representativo, características que no comparte con el CF. Por ende, consideramos que caben cuatro posibilidades a la hora de estudiar el discurso ficcional desde el punto de vista del grado de especialización:

a) Modificar las características atribuibles al CE de forma que puedan abarcar también al CF.

b) Crear una nueva categoría dentro del CG que se encuentre a caballo entre el CC y el CE, que haga referencia al CF.

c) Crear una categoría superior al CE, que podría denominarse conocimiento especial, en la que se incluya el conocimiento ficcional y el conocimiento especializado.

d) Crear una estructuración multicriterio que permita abarcar todas las manifestaciones del conocimiento e integrar los tipos de conocimiento que aquí analizamos.

A nuestro juicio, proponer una nueva estructuración del mapa conceptual en torno a los tipos de conocimiento es la propuesta más útil en relación con su proyección teórica, puesto que no hace necesario modificar los conceptos hasta ahora analizados, sino situarlos en una nueva red de relaciones y niveles que atiendan a diferentes criterios, como son su relación con la realidad o la irrealidad, su motivación funcional o el grado de comprensibilidad. Con todo, debe destacarse que la propuesta de reestructuración se entiende desde un punto de vista sincrónico desde el marco de la teoría de prototipos de la lingüística cognitiva (Rosch, 1978), de forma que una categoría está compuesta por entidades que son más o menos 
prototípicas o ideales y por entidades más o menos periféricas con respecto al prototipo, con limites que no son claro, sino más bien difusos y poco delimitados. En este caso, el prototipo constituye la entidad que mejor representa al conjunto de entidades de la categoría.

\title{
5. EL CONOCIMIENTO FICCIONAL COMO FORMA DE ACERCAMIENTO AL CONOCIMIENTO DEL MUNDO
}

Al estudiar el CE, Cabré (1998a: 186) afirma que constituye solo una de las posibles vías de conceptuación de la realidad, por lo que, en principio, cabría asumir a priori que el CF constituye otra de estas vías. Por otro lado, resulta especialmente relevante el modelo de representación del conocimiento de Monterde Rey (2004), que divide la representación del concepto a través de formas lingüísticas, formas no lingüísticas y objeto. En este sentido, la autora distingue entre objetos materiales y objetos inmateriales. En palabras de Monterde Rey $(2004,58)$, «un objeto material es concreto; es decir, perceptible a través de los sentidos, mientras que un objeto inmaterial es mental o pensado; esto es, imaginable». A su vez, dentro de esta última categoría, distingue entre objetos materializables y objetos inmaterializables, que define del siguiente modo (2004: 58-59):

\begin{abstract}
Los materializables son objetos mentales que todavía no se han materializado, pero que podrían materializarse en un futuro. Un ejemplo puede ser un nuevo modelo de bicicleta que una persona ha ideado, ha descrito e incluso de la que ha hecho un croquis, pero todavía no ha construido. Los objetos inmaterializables, por el contrario, son aquellos objetos mentales que no pueden adquirir una forma material. Por ejemplo, un nuevo impuesto ecológico descrito por una persona solo podría tener una realización lingüística (nombre + descripción).
\end{abstract}

Aplicando esta categorización de los objetos a nuestro estudio sobre el $\mathrm{CF}$, podemos afirmar que la ficción se compone de objetos inmateriales, ya que hacen referencia a objetos que no existen realmente (aunque puedan estar basados en objetos del mundo real o que contengan rasgos distintivos de objetos reales). No obstante, consideramos que la denominación de materializable e inmaterialiazable puede llevar a confusión y se aleja de nuestra perspectiva de estudio (puesto que, realmente, ningún objeto ficcional puede materializarse a priori). En este sentido, proponemos la denominación de objetos inmateriales posibles e imposibles, que desarrollaremos posteriormente.

Por otra parte, dejando de lado las aproximaciones terminológicas al estudio de la representación del conocimiento, es posible asimismo encontrar 
algunas teorías de la filosofía del lenguaje y la teoría literaria que apoyan nuestro presupuesto acerca del CF como forma de acercamiento al conocimiento de la realidad.

Peter Lamarque (2010: 368), reconoce la falta de límites claros entre ficción y no ficción. Defiende que la literatura ${ }^{8}$ permite una forma de aprendizaje sobre el mundo real que, de acuerdo con Aristóteles, se produce por medio del placer (función poética o expresiva, finalidad lúdica). Del mismo modo, señala que tanto Platón como Aristóteles concuerdan en que la literatura es un tipo de imitación o mímesis del mundo real (Lamarque 2010, 369). Según Lamarque, para Aristóteles la literatura puede aspirar a la verdad sobre las cosas, puesto que la imitación de los objetos puede presentarse de muchas formas: como son o fueron, como se dice o se piensa que son o fueron, o como deberían ser (Lamarque, 2010: 369-370). Resulta interesante esta consideración de Lamarque al respecto del pensamiento aristotélico, puesto que sostiene que la literatura puede aspirar a la verdad no solo describiendo hechos factuales (objetos materiales o inmateriales), sino también «aquello que podría ser» (objetos posibles o imposibles). En este sentido, la ficción y, por ende, el CF, constituirían un modo de acercarse al conocimiento del mundo (o, como hemos denominado previamente, conocimiento genera).

No obstante, conviene no dejar de lado el propósito lúdico de la ficción. Como recuerda Lamarque (2010: 382), si bien la ficción supone una forma de acercamiento al conocimiento sobre el mundo, con frecuencia el lector que se enfrenta a una obra de ficción no tiene expectativas cognitivas; es decir, la motivación para la lectura no es el pensamiento de que va a aprender algo, sino el placer estético de la lectura, a pesar de que ello tenga como consecuencia la adquisición de conocimientos que puedan cambiar su conocimiento sobre el mundo.

Nelson Goodman, siguiendo un enfoque nominalista, plantea en su obra Ways of Worldmaking la cuestión de la cognición del mundo y su relación con los símbolos y el arte. El autor señala que los mundos de la ficción, la poesía, la pintura o la música se construyen en gran parte a partir de recursos

${ }^{8}$ A pesar de que a menudo se identifica la ficción con la literatura, o viceversa (a pesar de que la ficción puede manifestarse en otras producciones semióticas), consideramos oportuno aclarar que se trata de dos conceptos diferentes. A nuestro parecer, y como indican autores como Lamarque y Olsen (1994: 255), la literatura es un concepto evaluativo, mientras que la ficción es un concepto meramente descriptivo determinado por el propósito comunicativo y la intención del autor. Asimismo, no se puede afirmar que ninguno de los conceptos incluya al otro. No obstante, dado que, hasta la aparición de nuevas producciones discursivas como el cine o los videojuegos, la ficción se manifestaba prototípicamente en textos literarios, es común encontrar aportaciones teóricas que identifiquen ambos conceptos. 
no literales como la metáfora y recursos no denotativos como la ejemplificación y la expresión (Goodman, 1978: 101). En este sentido, para el autor el arte debe considerarse en el mismo nivel que la ciencia en cuanto a la forma de aproximación del conocimiento sobre el mundo y al modo de descubrimiento y comprensión de las cosas.

El autor aborda la cuestión de cómo los elementos que no denotan nada en la realidad (por ejemplo, Don Quijote) pueden ayudar a comprender el mundo real. Así, por ejemplo, Don Quijote, tomado de manera literal, no hace referencia a nadie, pero entendido de manera figurada, se aplica a muchas personas. Continúa Goodman exponiendo que la aplicación del término ficcional Don Quijote a personas reales, al igual que la aplicación metafórica del término no ficcional Napoleón a otros generales, o la aplicación de términos recientemente acuñados como vitamina o radioactivo a algunos materiales, supone una reorganización del mundo conocido, de modo que la metáfora, como mecanismo cognitivo, no constituye únicamente un recurso retórico decorativo o estético, sino también una vía por la que los términos alumbran conocimiento sobre la realidad.

La ficción, de este modo, se aplica y hace referencia al mundo real (1978: 103-104), de forma que los denominados mundos posibles de la ficción descansan en el mundo real. No obstante, a diferencia del CE, de carácter referencial, el CF exige una tarea interpretativa por parte del receptor, que incorpora el conocimiento adquirido por la ficción a su conocimiento sobre el mundo real en función de sus necesidades cognitivas.

\section{LA REFERENCIALIDAD DE LAS ENTIDADES FICCIONALES CON RESPECTO AL MUNDO REAL}

En el prólogo de su obra Heterocosmica, Doležel señala que la ficcionalidad (fictionality) es un tema recurrente en la filosofía y la lógica modernas, especialmente en lo que respecta al carácter ontológico de los particulares ficcionales (1998: 1-2). Para el autor, la ficcionalidad puede definirse como un fenómeno principalmente semántico situado en el eje representación (signo)-mundo, aunque no pierde de vista los aspectos formales y pragmáticos (1998: 2).

Como apunta asimismo Doležel, la mayoría de teorías que analizan el carácter ontológico de las entidades ficcionales se basan en la referencialidad de las mismas con respecto al mundo real y parten del presupuesto de que solo existe un universo legítimo de discurso (dominio de referencia). Filósofos analíticos como Bertrand Russell consideran que las palabras que aluden a 
entidades ficcionales son términos vacíos ${ }^{9}$ (empty terms), ya que no existen porque carecen de referencia al mundo real $\mathrm{y}$, por tanto, las proposiciones ficcionales son falsas. Una postura similar es la de Gottlob Frege (recogido en Doležel, 1998: 3-4), para el que el tratamiento semántico de la ficción descansa en su diferenciación entre referencia y sentido. Así pues, el sentido haría referencia al concepto, aquello que dice la proposición, mientras que la referencia o denotación aludiría al objeto (recogido en Ricoeur, 1975: 273278). De este modo, según Frege, a un signo le correspondería un sentido y una denotación determinados, mientras que una sola denotación podría corresponder a más de un signo.

Otra postura similar es la de Nelson Goodman (1976, 21), que afirma que algunas representaciones pueden no tener ninguna denotación. De este modo, hablar de Pickwick (personaje de Charles Dickens) o de un unicornio sería lo mismo, pues ninguno representa nada: no tienen denotación. Sin embargo, a pesar de que representan lo mismo (es decir, nada), es posible diferenciarlos y aluden a distintos conceptos. Por tanto, puede extraerse la conclusión de que, para Goodman, un término ficcional carece de referente.

Por su parte, Paul Ricoeur (1975, 273), en su estudio sobre la metáfora, distingue asimismo los conceptos de sentido y referencia, partiendo para su hipótesis de la teoría de Frege. Sin embargo, Ricoeur (1975: 277-278) sugiere que en el texto literario se da una situación especial, en la que la estructura de la obra constituye el sentido y, el mundo de la obra, su denotación. Así pues, la producción de un discurso como literatura supone que la relación entre el sentido y la referencia se suspende. De este modo, la literatura constituye un tipo de discurso en el que no existe referencia o denotación, sino solo connotación.

En la obra literaria, el discurso despliega su denotación como una denotación de segundo rango, a favor de la suspensión de la denotación de primer rango del discurso (Ricoeur, 1975: 278-279). Ricoeur relaciona este postulado con el enunciado metafórico, ya que considera que es el ejemplo más claro que muestra la suspensión de la referencia de primer rango y activa la segunda. Es en este punto donde se cuestionan los conceptos de realidad, verdad y mundo.

En referencia a la cuestión sobre la diferencia entre real e imaginario, Ricoeur (1975: 288) sostiene que su teoría sobre la denotación se basa en que la suspensión de la referencia, en el sentido definido por las normas del

\footnotetext{
${ }^{9}$ La denominación de término por Bertrand Russell no debe confundirse con la que suele otorgarse a las unidades que representan el CE por oposición a la palabra, sino que se emplea aquí como sinónimo de palabra, como forma lingüística que representa un concepto.
} 
discurso descriptivo, es la condición negativa para que se despeje un modo más fundamental de referencia, que es la tarea de la interpretación de explicitar. Esta explicitación tiene como desafío el sentido mismo de las palabras realidad y verdad. Por tanto, la suspensión de la referencia real constituye la condición de acceso a la referencia al modo virtual. Del mismo modo, plantea la cuestión de si la función de la poesía es la de crear un mundo con otras posibilidades de existir realizables (objetos posibles e imposibles). Puede observarse, por tanto, que Ricoeur diferencia entre la referencia o denotación al mundo real y al modo virtual (mundo ficcional), que se corresponden con la denotación de primer rango y segundo rango.

Por otra parte, conviene asimismo aludir a la teoría de la mímesis, desarrollada expresamente a lo largo de varios siglos como teoría de las representaciones ficcionales. Su idea principal se apoya sobre el presupuesto de que las entidades ficcionales son imitaciones de la realidad (Doležel, 1998: 6-10). Del mismo modo, el autor de una obra de ficción necesita una base para desarrollar su ficción, por lo que debe basarse imperativamente en el mundo real para transgredir sus leyes o imaginar alternativas ${ }^{10}$. El presupuesto básico de la interpretación mimética consiste en asignar un prototipo real a una entidad ficcional, lo cual puede expresarse de manera sintética como:

Un particular ficcional $P(f)$ representa un particular real $P(r)^{11}$.

Al asignar un prototipo real a un concepto ficcional, se provee al término ficcional de una referencia semántica, de forma que el universo del discurso del mundo ficcional resulta ser el mundo real. Sin embargo, Doležel (1998: 7) señala que el problema de la aceptación de esta teoría surge cuando no sabemos dónde buscar el prototipo, y cita los ejemplos de Hamlet o Julien Sorel. La conclusión a la que llega el autor es que, puesto que en muchos casos una entidad ficcional no se corresponde con un particular real, es necesario realizar una desviación interpretativa, de modo que los particulares ficcionales se toman como representaciones de universales

\footnotetext{
${ }^{10}$ Por ejemplo, una sirena, entendida en el sentido amplio del término y sin adscribirnos a las connotaciones que pueda adquirir para una determinada cultura, es una criatura con aspecto de mujer y de pez; así, a pesar de que no exista una criatura como tal en el mundo real, es necesario recurrir a nuestro conocimiento sobre lo real (qué es una mujer y qué es un pez) para poder conceptualizar el concepto de sirena. En definitiva, aunque el concepto ficcional sea absolutamente imposible en el mundo real y carezca de una referencia directa con un elemento de la realidad, es necesario que exista un vínculo con el conocimiento del mundo para poder comprenderlo y asimilarlo.

${ }^{11}$ El ejemplo ofrecido por Doležel (1998: 6-7) es el de Riothamus, rey de los bretones en Bretaña, que se toma como prototipo histórico del legendario Rey Arturo. Otro ejemplo aún más claro es el Londres de Dickens o el Napoleón de Tolstoi, que designan nombres con un equivalente en el mundo real.
} 
reales 0 arquetipos de la realidad. En este caso, la función mimética podría representarse de esta forma:

Un particular ficcional $\mathrm{P}(\mathrm{f})$ representa un universal real $\mathrm{U}(\mathrm{r})^{12}$.

Sin embargo, de nuevo el autor pone en tela de juicio esta consideración sobre la interpretación mimética, pues exige al intérprete o receptor llevar a cabo una operación dual. En primer lugar, debe realizar un proceso de abstracción para transcribir la realidad y categorizarla en arquetipos (prototipos universales) y, en segundo lugar, debe adjudicar los particulares ficcionales a una de estas categorías para que puedan ser interpretados. Consistiría, por tanto, en un doble proceso de concreciónabstracción-concreción, que no dejaría de ser subjetivo y condicionado por múltiples factores circunstanciales al receptor.

A pesar de que consideramos que la mímesis no puede dar cuenta de una teoría de la ficcionalidad y tiene un carácter limitado, puesto que solo sirve para explicar la referencialidad de las entidades ficcionales que pueden asociarse con un prototipo real (particular o universal), consideramos que, en efecto, el CF está indiscutiblemente ligado a la realidad: todos los elementos que forman parte de la situación comunicativa (emisor, receptor, canal, mensaje y código) pertenecen al mundo real, por lo que es evidente que el autor de una obra de ficción se basará en la realidad para desarrollar la ficción y, por ende, el receptor también estará condicionado por su entorno real a la hora de realizar la tarea interpretativa. Por otro lado, si bien es cierto que las entidades ficcionales carecen de referencia a objetos reales, consideramos pertinente recurrir al modelo de representación de Monterde Rey (2004) para distinguir entre los objetos materiales y objetos inmateriales (que se subdividen en posibles e imposibles) y matizar que las entidades ficcionales no denotan objetos materiales, pero sí pueden denotar y hacer referencia a objetos inmateriales, por lo que no consideramos que carezcan por completo de referencialidad.

Por su parte, tras abordar las principales teorías que tratan la naturaleza ontológica de las entidades ficcionales y su referencialidad al mundo real, Doležel propone su propia teoría sobre los mundos posibles. Para ello, recurre a un enfoque semántico, basándose en la corriente semántica de los mundos posibles, y parte del presupuesto de que el mundo real o factual está rodeado de una infinidad de mundos posibles o no actualizados, con particulares posibles, basándose en la lógica semántica

\footnotetext{
${ }^{12}$ Así, por ejemplo, el personaje de Don Quijote o Sancho son representativos de la vida y la cultura española en el Siglo de Oro, siguiendo a Auberbach (Doležel, 1998: 7-8), y responden a arquetipos como antihéroe o siervo leal.
} 
(Doležel, 1998: 12-13) ${ }^{13}$. Aplicando este presupuesto a nuestro objeto de estudio, nos encontraríamos en este caso ante el aspecto creativo de la literatura, que permite desarrollar la imaginación humana.

El autor, pues, desarrolla una teoría de la ficcionalidad inspirada en la semántica de los mundos posibles. Para Doležel (1998: 16-18), los mundos ficcionales son conjuntos de estados de cosas no materializados; es decir, representan objetos inmateriales, si nos adscribimos al modelo de representación del conocimiento de Monterde Rey $(2004)^{14}$. No obstante, para Doležel, al tratarse de entidades no realizadas (no materiales), todas las entidades ficcionales tienen la misma naturaleza ontológica (por lo que el Londres de Dickens no sería más real que el País de las Maravillas de Lewis Carroll). No obstante, consideramos que, aunque desde un punto de vista ontológico todos los particulares ficcionales tienen la misma naturaleza (no existen ni se refieren a un objeto del mundo real), pueden dividirse en dos categorías teniendo en cuenta un enfoque epistemológico.

De este modo, podríamos distinguir entre particulares ficcionales posibles y particulares ficcionales imposibles si bien deben entenderse como categorías cognitivas (Rosch, 1978) y, por tanto, dinámicas. En el primer caso, nos referimos a aquellos conceptos que designan objetos materializables (según el modelo de representación de Monterde Rey, 2004), es decir, entidades que no existen en el mundo real pero que podrían existir o haber existido porque se ajustan a la lógica y las leyes que rigen el mundo real. En el caso de los particulares ficcionales imposibles, nos encontraríamos ante un concepto modificado de los objetos inmaterializables de Monterde

\footnotetext{
${ }^{13}$ Conviene realizar en este sentido una aclaración denominativa al respecto del término posible. Aunque Doležel utiliza esta denominación para hablar de mundos o particulares no actualizados (no presentes en la realidad, pero susceptibles de ser creados), nosotros recurriremos a esta denominación para denominar los particulares ficcionales materializables (conceptos que no existen en el mundo real pero podrían existir porque se adecúan a las reglas y la lógica del mundo factual), por oposición a los particulares ficcionales imposibles o inmaterializables (aquellos conceptos que no existen en el mundo real ni podrían existir de acuerdo con la lógica que rige el mundo real). Por tanto, excepto al hacer referencia a la teoría del filósofo checo, utilizaremos el término posible en este sentido.

${ }^{14}$ Para sustentar esta afirmación, Doležel ilustra que, aunque Hamlet no es un hombre que pueda encontrarse en el mundo real, es un individuo no materializado que habita en un mundo alternativo (el mundo ficcional de la obra de Shakespeare). No obstante, el autor recalca que estos particulares ficcionales tienen un carácter ontológico distinto de los particulares reales. A diferencia de la semántica mimética, donde en ocasiones la distinción entre los particulares reales y ficcionales es difusa (sobre todo cuando comparten un nombre), en la semántica de los mundos posibles no existe esta ambigüedad, porque el Napoleón real y el Napoleón de Tolstoi o el Londres real y el Londres de Dickens son diferentes, pues los particulares ficcionales no dependen para su existencia de los prototipos reales, aunque evidentemente existe una relación entre ambos.
} 
Rey (2004): aquellas entidades que no existen en el mundo real ni podrían existir o haber existido porque no cumplen las reglas y lógica del mundo real ${ }^{15}$.

Además del carácter no materializado o no realizado que caracteriza a los mundos ficcionales de la teoría de Doležel, el autor indica que el conjunto de mundos ficcionales es ilimitado y diverso (de ahí la denominación que ofrece de mundos posibles). Por tanto, la ficción no se limita a imitar el mundo real (como plantean las teorías miméticas), puesto que la ficción permite crear mundos posibles ilimitados, aunque incompletos. Asimismo, el autor matiza que los mundos ficcionales solo son accesibles a través de canales semióticos: para pasar de lo real o factual a lo no realizado o ficcional, el emisor y el receptor solo pueden acceder al CF a través de un texto o discurso ficcional. Se trata, por tanto, de una accesibilidad bidireccional, que implica que el autor o emisor construye el mundo ficcional y el lector o receptor lo reconstruye. Es decir, a diferencia del $\mathrm{CE}$, que tiene un carácter representativo y referencial, pues representa, describe y explica la realidad, el CF es producto de la creatividad humana y solo puede ser adquirido a través de un canal semiótico.

La tesis de Doležel, aun siendo revisable, se centra de manera específica en el análisis de la ficción con respecto a su pertenencia al mundo real y trata los términos que aluden a entidades ficcionales (fictional particulars para él, o irrealia para Loponen, 2006). Se trata, por lo tanto, de una teoría filosófico-literaria que aborda directamente el objeto de estudio del presente trabajo. Por lo que respecta a las teorías miméticas, reconocen la existencia de una referencialidad o conexión con el mundo real por medio de referencias directas (prototipos) o procedimientos de abstracción (arquetipos universales), pero consideramos que esta postura tampoco da cuenta de todos los casos y solo se limita a algunos ejemplos. La teoría de Doležel, no obstante, reconoce la referencialidad de las entidades ficcionales al mundo real y el papel intermediario del texto ficcional como agente que permite la interacción entre el emisor y el receptor, que construye y reconstruye la obra, que no deja de ser un objeto semiótico surgido a partir de la creatividad humana y, por lo tanto, está forzosamente relacionado con el mundo real, en tanto en cuanto el emisor forma parte de él, junto con el receptor.

\footnotetext{
15 Siguiendo el ejemplo de Doležel para ilustrar nuestra clasificación, aunque el Londres de Dickens o el País de las Maravillas de Carroll tienen la misma naturaleza ontológica, desde un punto de vista epistemológico difieren notablemente: mientras que Dickens representa una ciudad de Londres que podría haber existido y que se ajusta a las leyes de la naturaleza y la lógica del mundo real (objeto materializable), Carroll nos habla de un país imaginario en el que se transgreden las leyes naturales y se producen situaciones que no podrían darse en la vida real.
} 
7. Catalogación de los tipos de conocimiento: Propuesta de RECLASIFICACIÓN

Así, partiendo del CG (es decir, del conocimiento que abarca toda la realidad, tanto lo factual como lo imaginario), a nuestro juicio es posible dividir los tipos de conocimiento atendiendo a dos criterios:

a) En primer lugar, atendiendo a la existencia o inexistencia de categorías ontológicas ${ }^{16}$ en el mundo factual, lo que nos permite distinguir entre conocimiento de lo real o factual y conocimiento de lo irreal o imaginario ${ }^{17}$.

b) En segundo lugar, atendiendo a la motivación que permite generar dicho conocimiento. En este punto es donde puede hallarse un elemento de encuentro que implica gradación, la cual permite explicar los trasvases y la comprensibilidad entre tipos de conocimiento. Así, hablamos de $\mathrm{CE}$, que parte del conocimiento de lo real; de CF, que parte del conocimiento de lo irreal; y de CC, que hace referencia al conocimiento que comparten los grupos sociales a causa de su experiencia cotidiana con el mundo. Dependiendo del grupo y de dicha experiencia, el conocimiento compartido será más o menos diferente.

De forma gráfica, proponemos el siguiente esquema:

\footnotetext{
${ }^{16}$ Las categorías ontológicas de la realidad, según Sager (1990), Kageura (1997), Sager y Kageura (1994/1995) y Vendler (1967), entre otros, son: objetos/entidades, eventos/procesos, atributos y relaciones.

17 A este respecto, si bien hemos defendido que el conocimiento ficcional es una forma de conocimiento sobre el mundo real y que la ficción está necesariamente conectada con la realidad (al tratarse de un acto comunicativo que tiene lugar en un contexto real), nos referimos en este caso al conocimiento de lo material o tangible y el conocimiento de lo imaginario o creado a raíz de un procedimiento creativo.
} 


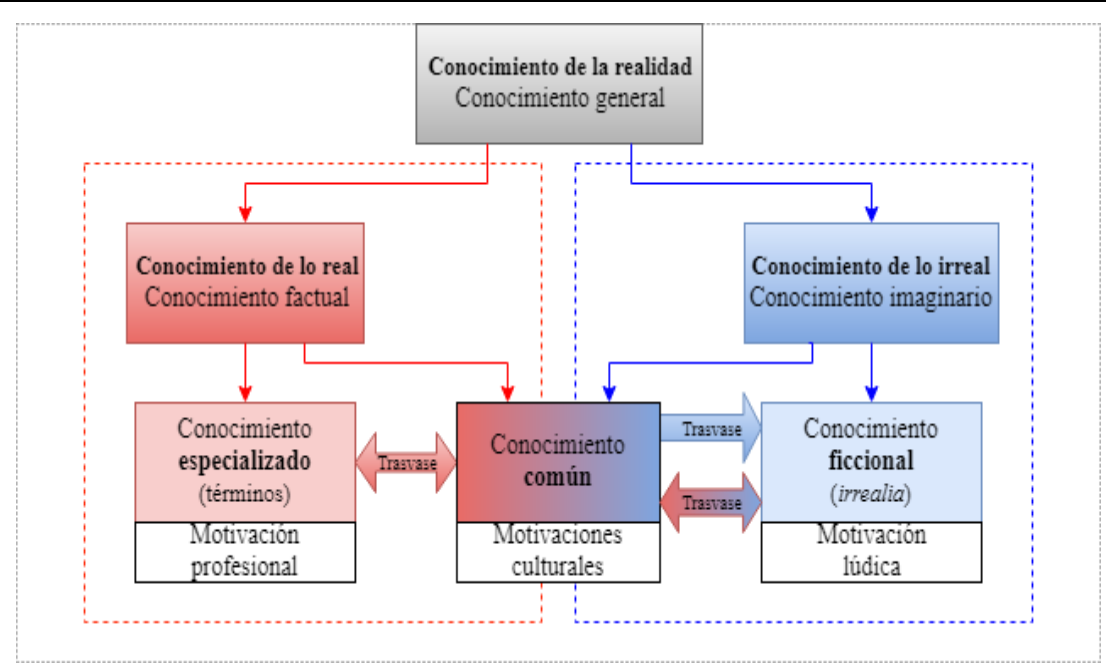

FIGURA 2. Propuesta de reestructuración de los tipos de conocimiento

Fuente: elaboración propia

De acuerdo con este esquema, el CG (que identificamos con el conocimiento de la realidad y del mundo que nos rodea) puede subdividirse en dos tipos de conocimiento que permiten comprender el mundo real: el conocimiento de lo real o factual, al que se accede por medio del CC y el CE, ya sea por motivaciones culturales, sociales o profesionales, y que da cuenta de la realidad material e inmaterial observable a través de los sentidos y la razón, con una función referencial y representativa; y, por otro lado, el conocimiento de lo irreal o imaginario, que puede ser CC (motivado también por factores culturales y sociales, como ocurre en la mitología, por ejemplo), y el CF, caracterizado por una motivación lúdica, y que requiere la capacidad creativa del emisor y la reconstrucción interpretativa del receptor.

Asimismo, conviene observar que, cuando la realidad cotidiana y la realidad del avance científico entran en contacto, ya sea de forma concreta o permanente, en el caso del CE y CC, se produce una interrelación bidireccional, de modo que es posible que unidades léxicas del discurso común pasen a denominar conceptos especializados mediante procesos de terminologización (por ejemplo, el caso de vaso), del mismo modo que es posible que términos especializados pasen a formar parte del CC por medio de procedimientos de desterminologización y banalización (prima de riesgo, anemia). Sin embargo, el trasvase entre el CC y el CF es bidireccional restringido: solo las unidades léxicas del discurso común pueden pasar a formar parte del CF (centauro, dragón, cenobita), pero en muy raras 
ocasiones un irrealia creado expresamente en el marco del discurso ficcional pasa a formar parte del discurso común (replicante, huargo o hobbit son irrealia que no pueden pasar al discurso común puesto que no denotan un objeto material real). Que no pase a formar parte del caudal léxico del discurso común no supone que, en ocasiones, los irrealia sean empleados por los hablantes en determinados entornos socioculturales. Un ejemplo sería «parece un orco» para hacer referencia a alguien o algo de aspecto desagradable o «habla como Yoda» para referirse a un modo de hablar peculiar. No obstante, para que pasaran a formar parte del discurso común, sería necesario que todos los hablantes accedieran al discurso ficcional en el que son creados estos irrealia y adquirieran dicho CF. Es decir, para que un irrealia como huargo o hobbit pasaran al discurso común las obras ficcionales de Tolkien deberían ser conocidas por toda la comunidad lingüística y deberían poder aplicarse a objetos del mundo real mediante recursos como la metáfora o metonimia (por ejemplo, al asociar personas de baja estatura con hobbits o perros muy grandes con huargos, por plantear una situación hipotética):

a) En el caso de tradiciones culturales, puede afirmarse que el CF aporta conocimiento al CC (compartido por grupos sociales): sirena, orco, dragón, valkiria, etc. De hecho, estas unidades surgen a caballo entre el CC y el CF (algo que, por ejemplo, no ocurriría con los culturemas, que nacen y se desarrollan exclusivamente en el seno del CC, y no se aproximan al CE) ${ }^{18}$. Las razones que explican este trasvase son que el concepto ya existía antes que la propia denominación y que, además, se trata de conceptos ligados a tradiciones culturales.

b) En el caso de creaciones ficcionales individuales (El Señor de los Anillos, Star Wars, Harry Potter, etc.), el CC es el que aporta todo el conocimiento al CF, y no suele ser de forma contraria.

La categoría de CF incluye todo aquello que pueda tener cabida en un discurso ficcional ${ }^{19}$, desde una novela histórica hasta una película futurista 0 un cómic de terror. Pero surgen algunas preguntas relacionadas: ¿qué definiría este tipo de conocimiento?, ¿qué parámetros se utilizan para

18 Los culturemas también pueden ser irrealias. Por ejemplo, una valkiria puede tratarse como un culturema de las mitologías nórdicas y germánicas pero, a su vez, se cataloga como irrealia, puesto que se trata de un objeto inmaterializable, pero siempre en el marco de un discurso ficcional. Es decir, los irrealia activan su condición semántica según factores pragmáticos.

${ }^{19}$ En realidad, pueden incluirse todos los contextos susceptibles de generar ficción. Aunque tradicionalmente esta capacidad se ha reservado a la literatura (también la pintura, aunque de manera menos prototípica), en los últimos tiempos pueden mencionarse otros canales semióticos como el cine, los cómics o los videojuegos. 
colocarlo al mismo nivel que el CE y el CC?, ¿no podría formar parte del CG? Al fin y al cabo, la comprensión de un texto ficcional parte del bagaje cultural y del conocimiento general del individuo. Cualquier persona puede leer $E l$ Señor de los Anillos de J. R. R. Tolkien, pero comprenderán mejor la obra aquellos receptores familiarizados con las mitologías germánicas, griegas y nórdicas, los cantares épicos y la corriente romántica o las historias épicas anglosajonas (es decir, aquellas personas familiarizadas con la semiosfera del género literario en cuestión). Del mismo modo, cualquier persona puede leer 1984 de George Orwell, pero la entenderán mejor aquellos receptores que tengan conocimientos históricos y sociopolíticos sobre el comunismo ${ }^{20}$.

Teniendo en mente el criterio de comprensibilidad, es posible recurrir a la variación para explicar cómo es posible situar el CF al mismo nivel que el CE y el CC. La comunicación especializada (marco y vehículo que transmite $\mathrm{CE})$ se inscribe en un tipo de variación diafásico-diastrática (Casas, 2003: 570) que provoca una desviación del modelo comunicativo idealizado, así como de la función principal en la lengua. Esto sucede de la misma forma con el CF. Por esta razón, consideramos que el criterio discriminante puede ser el mismo. De forma similar a cómo los textos se gradúan en diferentes niveles de especialización, dependiendo de factores pragmáticos y cognitivos, puede encontrarse en el CF (y sus productos textuales), casos más o menos comprensibles para todo el mundo (Heller, 1970: 532), que dependen directamente (no del conocimiento profesional del receptor, como en el CE) sino del bagaje sociocultural del receptor. De esta forma, también podrían distinguirse niveles de ficción (a través del criterio de comprensibilidad).

Sin embargo, mientras que la terminología puede encontrarse en diferentes tipos de textos con una gradación variable de especialización, un particular ficcional (o irrealia, según la denominación de Loponen, 2006) solo tiene sentido en un texto concreto. Al aislarlo puede no comprenderse, pero el autor siempre explicará a qué hace referencia.

\footnotetext{
${ }^{20}$ Asimismo, este tipo de obras pueden aportar conocimiento sobre el mundo real a través de las alusiones miméticas, abstracciones o recursos metafóricos. Por ejemplo, citando los casos anteriormente mencionados, según la interpretación llevada a cabo por el receptor, El Señor de los Anillos puede ayudar al receptor a reflexionar sobre conceptos abstractos como la amistad, la dicotomía sobre el bien y el mal, las consecuencias del poder, etc., pero también aporta conocimiento indirecto sobre las mitologías nórdicas o germánicas, al estar pensado para imitarlas. Asimismo, el lector de 1984 puede adquirir conocimiento sobre las características de una corriente política concreta, sus consecuencias positivas y negativas y relacionarlo con determinados periodos históricos. No obstante, esta adquisición de conocimiento sobre el mundo real depende de las expectativas cognitivas del receptor al acceder a la obra y no se manifiestan de manera explícita o como propósito fundamental de la obra de ficción.
} 
Por tanto, independientemente del bagaje cultural del receptor, que comprenderá más o menos la obra, dicha comprensión viene asimismo dada por el propio texto. La comprensión del término neón dependerá del grado de especialización de un texto, mientras que, en el caso de cruciatus, el lector de Harry Potter lo comprenderá perfectamente desde el momento en que lea la obra. Es importante tener en cuenta que los irrealia o particulares ficcionales solo tienen sentido en el texto en el que se presentan y fuera de él pierden todo su valor denotativo.

Las categorías difusas impiden establecer límites nítidos, pero sí hacen posible contar con un marco general dividido de forma tripartita, en el que el CC constituye el eje de convergencia y trasvase y el CF y el CE representan polos de oposición e interrelación (Moreno Paz y Rodríguez Tapia, en prensa). Una clasificación tripartita es útil desde la perspectiva teórica, ya que permite trabajar con objetos idealizados o prototípicos. No obstante, es importante reconocer la gradación del fenómeno, ya que esta se encarga de alejar los casos de dichos objetos idealizados. La utilidad de la gradación y los problemas teórico-metodológicos tiene también lugar en el discurso especializado, como se comprueba en trabajos como el de Rodríguez-Tapia (2016).

Por tanto, nos aproximamos a la definición de conocimiento ficcional de la siguiente forma: se trata del conocimiento de mundos ficcionales (posibles o imposibles) distintos del mundo factual, adquirido a través de textos o discursos con una función expresiva y motivación lúdica, creados a partir de la imaginación de un individuo o grupo de individuos, y condicionados, por lo tanto, por su creatividad y situación comunicativa. Se trata, no obstante, de un conocimiento restringido e incompleto, al solo tener sentido en un contexto determinado (una novela, una película, un videojuego, etc.) y surgir de la creatividad de su autor, que limita y condiciona, por tanto, la comprensión de dicho $\mathrm{CF}^{21}$. Asimismo, se trata de un tipo de conocimiento que solo puede transmitirse a través de un canal semiótico y que requiere una labor interpretativa de reconstrucción por parte del receptor, que asimila el CF y lo relaciona con el conocimiento del mundo real según sus necesidades cognitivas.

\footnotetext{
${ }^{21}$ Para ilustrar dicho conocimiento es posible recurrir a diferentes ejemplos. Se puede no saber qué es un protón pero puede documentarse en textos divulgativos o especializados, según el grado de conocimiento que se tenga sobre el tema, el bagaje cultural o educativo, etc. Sin embargo, para saber qué es un hobbit, solo se dispone de la información contenida en la obra de Tolkien. Por otra parte, aunque el personaje de Don Quijote sea uno de los más estudiados y conocidos por todo el mundo, no sabemos (ni podemos saber) cuál es su comida favorita, pues Cervantes no incluye esa información sobre su personaje. De este modo, la descripción de los irrealia viene limitada por la información contenida en la ficción a la que pertenezca.
} 
Por tanto, enlazando lo estudiado con el tercer apartado relativo al marco de partida, recuperamos los parámetros delimitadores de las situaciones de comunicación anteriormente mencionados (Cabré y Estopà, 2005: 69) para caracterizar el CF:

a) En cuanto a las condiciones de recepción, y, en especial, en cuanto al receptor: el receptor accede al texto ficcional con una motivación lúdica, no con propósitos cognitivos. Asimismo, el texto ficcional es accesible a cualquier persona y está destinado al público general (al margen de las estrategias editoriales que puedan buscar dirigirse a un grupo social concreto), mientras que el texto especializado es solo accesible para un receptor experto o conocedor de la materia en cuestión, por lo que tiene un público destinatario restringido.

b) Por lo que respecta a la función básica: la comunicación del CF tiene una función eminentemente expresiva o estética, aunque puede adoptar una función referencial o representativa por medio de la interpretación mimética y la reconstrucción por parte del receptor, pero esta función es secundaria y no se da en todos los casos (depende de las expectativas cognitivas del receptor). Posee, de manera secundaria, una función autorreferencial, al ser representativo de sí mismo, es decir, del mundo ficcional que recrea.

En cuanto a la temática, a diferencia de la comunicación especializada, que necesita estar restringida a un ámbito especializado y parcelado del conocimiento, el texto ficcional depende de la creatividad del autor de la ficción y no tiene límites en cuanto a la temática, si bien se trata de un conocimiento incompleto, en tanto en cuanto solo se conoce aquello que el autor considera relevante.

\section{CONCLUSIONES}

En las páginas anteriores, hemos tratado de demostrar la existencia de una categoría de conocimiento distinta del conocimiento común y el conocimiento especializado, que permite también acceder al conocimiento general o conocimiento de la realidad. Para ello, hemos tenido en cuenta diferentes criterios como la (in)existencia de categorías ontológicas en el mundo real (lo que nos ha permitido distinguir entre el conocimiento de lo real o factual y el conocimiento de lo irreal o imaginario), así como la motivación que permite generar dicho conocimiento, que permitiría distinguir entre 
conocimiento especializado (motivación profesional), conocimiento común (motivación cultural) y conocimiento ficcional (motivación lúdica).

Asimismo, hemos tratado de llevar a cabo un intento de categorización y delimitación del conocimiento ficcional, caracterizado no solo por su motivación lúdica, sino también por su función principalmente expresiva y estética, su condición dependiente de las actividades creativas humanas (y, por tanto, su carácter limitado en cuanto a extensión) y su acceso a través de canales semióticos orientados a cualquier destinatario que, sin embargo, debe llevar a cabo una labor interpretativa de reconstrucción.

Por otra parte, uno de los aspectos fundamentales que conviene tener en cuenta para delimitar el conocimiento ficcional es la referencialidad de la ficción a la realidad. Tras examinar algunas teorías de la filosofía del lenguaje, hemos constatado que, si bien la ficción no puede hacer referencia a objetos materiales del mundo factual, gracias a recursos como las interpretaciones miméticas, la abstracción o los recursos metafóricos, existe una conexión entre el conocimiento ficcional y el conocimiento de la realidad, que solo puede establecerse entre el autor y su obra de ficción (construcción del mundo ficcional tomando como punto de partida la realidad) y la obra de ficción y el receptor (reconstrucción del mundo ficcional asociándolo con el entorno real). Del mismo modo, la teoría de mundos posibles nos permite considerar los textos ficcionales como constructos semióticos independientes y distinguir entre conocimiento ficcional materializable o posible (asociado a los mundos ficcionales que se rigen por las leyes naturales y la lógica del mundo real) y el conocimiento ficcional inmaterializable o imposible (asociado a los mundos ficcionales que se rigen por leyes naturales y lógicas distintas de la realidad factual).

No obstante, consideramos que, a pesar de haber llevado a cabo una primera aproximación a nuestra propuesta de categorización del conocimiento ficcional, se trata de una teoría que puede desarrollarse y ampliarse en futuros trabajos teniendo en cuenta una perspectiva interdisciplinar que no solo tenga en cuenta la filosofía del lenguaje, la terminología o la lingüística, sino también la teoría y crítica literaria. En este sentido, pensamos que una futura línea de investigación en relación con el presente trabajo podría pasar por asociar la representación del conocimiento ficcional con diferentes géneros literarios: de este modo, podríamos considerar a priori que la denominada literatura realista se asocia con el conocimiento ficcional posible, mientras que otros géneros como la literatura fantástica, algunas obras de la ciencia-ficción o de la literatura de terror representan conocimiento ficcional imposible. No obstante, consideramos que la afirmación y argumentación de estos presupuestos requeriría un 
análisis más profundo de la teoría y crítica literaria, por lo que consideramos que puede ser el punto de partida para futuras investigaciones.

Asimismo, consideramos pertinente estudiar con mayor profundidad las unidades de representación léxica del conocimiento ficcional: los llamados particulares ficcionales para Doležel (1998) y los irrealia para Loponen (2006). Para ello, sería necesario caracterizar y definir las unidades de representación léxica del conocimiento ficcional contrastándolas con las unidades de representación léxica del conocimiento especializado (los términos), de forma que nos permita encontrar puntos en común y divergentes que reafirmen nuestra nueva propuesta de clasificación del conocimiento y, concretamente, el concepto de conocimiento ficcional. En este sentido, en otros trabajos (Moreno Paz y Rodríguez-Tapia, 2018) hemos llevado a cabo una primera aproximación a esta caracterización lingüística en contraste con los términos del discurso especializado.

\section{REFERENCIAS BIBLIOGRÁFICAS}

Adelstein, A. (2004). Unidad léxica y valor especializado: estado de la cuestión y observaciones sobre su representación. (Tesis doctoral). Institut Universtari de Lingüística Aplicada, Universitat Pompeu Fabra, Barcelona. Recuperado de https://bit.ly/2qQ4xJ7.

Cabré, M. T. y Estopà, R. (2002). El conocimiento especializado y sus unidades de representación: diversidad cognitiva. Sendebar, 13, 141153.

- (2005). Unidades de conocimiento especializado: caracterización y tipología. En M. T. Cabré y C. Bach. (Eds.), Coneixement, llenguatge i discurs especialitzat (pp. 69-93). Barcelona: Institut Universitari de Lingüística Aplicada. Universitat Pompeu Fabra.

Cabré, M. T. (1998). El discurs especialitzat o la variació funcional determinada per la temàtica: noves perspectives. Caplletra. Revista internacional de filología, 25, 173-194.

-, Domènech, M., Morel, J. y Rodríguez, C. (2001). Las características del conocimiento especializado y la relación con el conocimiento general. En M. T. Cabré y J. Feliu. (Eds.), La terminología científico-técnica: reconocimiento, análisis y extracción de información formal y semántica (pp. 173-186). Barcelona: Institut Universitari de Lingüística Aplicada. Universitat Pompeu Fabra. 
Casas, M. (2003). Hacia una tipología de la variación. En F. Moreno et al. (Coords.), Lengua, variación y contexto. Estudios dedicados a Humberto López Morales, vol. 2 (pp. 559-574). Madrid: Arco/Libros.

Doležel, L. (1998). Heterocosmica: Fiction and possible worlds. Baltimore, MD: John Hopkins University Press.

Frye, N. (1957). Anatomy of criticism: four essays. Princeton, NJ: Princeton University Press.

Garrido, A. (1997). Teorías de la ficción literaria. Madrid: Arco.

Goodman, N. (1976). Languages of art: an approach to a theory of symbols. Indianapolis, IN: Hackett Publishing Company.

- (1978). Ways of worldmaking. Indianapolis, IN: Hackett Publishing Company.

Heller, K. (1970). Der Wortschatz unter dem Aspekt des Fachwortes. Versuch einer Systematik. Wissenschaftliche Zeitschrift der Karl-MarxUniversität Leipzig. Gesellschafts- und Sprachwissenschaftliche Reihe, 19, 531-544.

Kageura, K. (1997). Multifaceted/Multidimensional Concept Systems. En S. E. Wright y G. Budin. (Eds.), Handbook of Terminology Management: Basic Aspects of Terminology Management (pp. 119-132). Amsterdam: John Benjamins.

Lamarque, P. y Olsen, S. (1994). Truth, fiction, and literature: A Philosophical Perspective. Oxford: Clarendon Press.

- (2010). Literature and truth. En G. L. Hagberg y W. Jost. (Eds.), A Companion to the Philosophy of Literature (pp. 367-384). London: Blackwell Publishing.

Loponen, M. (2006). Translating irrealia: Creating a semiotic framework for the translation of fictional cultures. Chinese Semiotic Studies, 2, 165175.

Lotman, Y. (1990). Universe of the mind: A semiotic theory of culture. Bloomington, IN: Indiana University Press.

Monterde Rey, A. M. (2004). Evolución de modelos de formas de representación del conocimiento a nivel terminológico: propuesta de un modelo actual. LSP y Professional Communication, 4(1), 49-68.

Montero, S. y Faber, P. (2008). Terminología para traductores e intérpretes. Granada: Tragacanto. 
Moreno Paz, M. C. y Rodríguez-Tapia, S. (2016). Los irrealia como unidades de representación léxica de los textos ficticios: puntos en común y de divergencia con las unidades de representación de los textos especializados. En A. Chica y J. Mérida. (Eds.), Creando redes doctorales, vol. 5 (pp. 79-82). Córdoba: Universidad de Córdoba.

- (2018). El discurso ficcional y los irrealia: tipos de conocimiento sobre la realidad y sus actualizaciones lingüísticas a través del léxico. Pragmalingüística, 26, 2018 [en prensa].

Real Academia Española (2014). Diccionario de la lengua española (23. edición) [Versión electrónica].

Ricoeur, P. (1975). La métaphore vive. Paris: Éditions du Seuil.

Rodríguez-Tapia, S. (2016). Los textos especializados, semiespecializados y divulgativos: una propuesta de análisis cualitativo y de clasificación cuantitativa. Signa: Revista de la Asociación Española de Semiótica, 25, 987-1006.

Rosch, E. (1978). Principles of Categorization. En E. Rosch y B. B. Lloyd, (Eds.), Cognition and Categorization (pp. 27-48). Hillsdale: Lawrence Erlbaum.

Sager, J. C. y Kageura, K. (1994/1995). Concept Classes and Conceptual Structures: Their Role and Necessity. Alfa, 7/8, 191-216.

- (1990). A Practical Course in Terminology Processing. Amsterdam: John Benjamins Publishing Company.

Searle, J. (1992). Expression and meaning: studies in the theory of speech acts. Cambridge: Cambridge University Press.

Vendler, Z. (1967). Linguistics in Philosophy. Ithaca, NY: Cornell University Press. 